\title{
Expression of F-actin-capping protein subunit beta, CAPZB, is associated with cell growth and motility in epithelioid sarcoma
}

\author{
Kenta Mukaihara', Yoshiyuki Suehara ${ }^{1 *}$, Shinji Kohsaka², Daisuke Kubota', Midori Toda-Ishii ${ }^{1,3},{ }^{1}$ Keisuke Akaike ${ }^{1,3}$, \\ Tsutomu Fujimura ${ }^{5}$, Eisuke Kobayashi ${ }^{4}$, Takashi Yao ${ }^{3}$, Marc Ladanyi ${ }^{6}$, Kazuo Kaneko ${ }^{1}$ and Tsuyoshi Saito ${ }^{3}$
}

\begin{abstract}
Background: A previous proteomics study demonstrated the overexpression of F-actin capping protein subunit beta (CAPZB) in tissue specimens of epithelioid sarcoma (EpiS). The aim of the present study was to elucidate the function of CAPZB in EpiS.

Methods: Cellular functional assays were performed in two EpiS cell lines using CAPZB siRNAs. In addition, comparative protein expression analyses using Isobaric Tags for Relative and Absolute Quantitation (i-TRAQ) method were performed to identify the specific proteins whose expression was dysregulated by CAPZB, and analysed the data with the Ingenuity Pathways Analysis (IPA) system using the obtained protein profiles to clarify the functional pathway networks associated with the oncogenic function of CAPZB in EpiS. Additionally, we performed functional assays of the INI1 protein using INI1-overexpressing EpiS cells.

Results: All 15 EpiS cases showed an immunohistochemical expression of CAPZB, and two EpiS cell lines exhibited a strong CAPZB expression. Silencing of CAPZB inhibited the growth, invasion and migration of the EpiS cells. Analysis of protein profiles using the IPA system suggested that SWI/SNF chromatin-remodeling complexes including INI1 may function as a possible upstream regulator of CAPZB. Furthermore, silencing of CAPZB resulted in a decreased expression of INI1 proteins in the INI1-positive EpiS cells, whereas the induction of INI1 in the INI1-deficient EpiS cells resulted in an increased CAPZB mRNA expression.
\end{abstract}

Conclusions: CAPZB is involved in tumor progression in cases of EpiS, irrespective of the INI1 expression, and may be a potential therapeutic target. The paradoxical relationship between the tumor suppressor INI1 and the oncoprotein CAPZB in the pathogenesis of EpiS remains to be clarified.

\section{Background}

Epithelioid sarcoma (EpiS) is a rare soft tissue sarcoma that affects young adults and is characterized by a tendency toward local recurrence and metastasis [1]. EpiS is classified into two subtypes according the clinicopathological features: a distal form that often arises in the distal extremities as a slow-growing nodule, and a proximal form that tends to arise in deeper areas of the pelvis, perineum and genital tract. Although the clinical course of proximal type may be more aggressive than that of

\footnotetext{
* Correspondence: ysuehara@juntendo.ac.jp

'Department of Orthopedic Surgery, School of Medicine, Juntendo

University, Hongo 2-1-1, Bunkyo-ku, Tokyo 113-8421, Japan

Full list of author information is available at the end of the article
}

distal type [2, 3], the clinical course is diverse, even for the same subtypes.

Although the molecular pathogenesis of EpiS remains unknown, deletion of the SMARCB1/INI1 tumorsuppressor gene (INI1) was recently reported in cases of proximal-type EpiS [4] and subsequently in cases of distal-type EpiS [5]. Loss of the INI1 expression is observed in approximately $80-90 \%$ of distal and proximal EpiS patients [6, 7], and INI1 genetic inactivation is considered to be responsible for tumorigenesis in cases of EpiS [8]. However, molecular biological aspects related to the progression of EpiS remain unclear, in addition to that associated with INI1, and few functional studies have focused on specific pathways in EpiS cases. 
With respect to gaining further insight into the biology of sarcoma, proteomics studies are a powerful approach. Our previous proteomic study demonstrated the CAPZB expression in the tumor tissues of EpiS [9]. In addition, CAPZB is known to increase actin filament depolymerization and capping, which promotes cell motility [10,11], although functions other than cell motility have not been reported so far. According to the Human Protein Atlas (http://www.proteinatlas.org), CAPZB is also expressed in normal tissue (lymphoid cells, seminiferous ducts, urothelium and placenta exhibited strong staining) and also in certain types of tumors (lymphoma and testicular cancer). In addition, several previous proteomic studies have identified the differential expression of CAPZB [12, 13]. However, the functional roles and clinical impacts of CAPZB expression in these tumors are unknown. Several previous studies have briefly described the functions of CAPZB [11, 14, 15], focusing on its role as a capping protein (CP). CPs are important for the dynamics of actin filament assembly and regulation of the cell shape and movement in vitro [16-19]. However, the functions of CAPZB in EpiS have not yet been elucidated.

In the current study, in order to elucidate the functions of CAPZB in EpiS, we performed functional assays using gene silencing of CAPZB in EpiS cell lines. Consequently, a proteomics study followed by a pathway analysis revealed the SWI/SNF chromatin remodeling complex, which includes INI1, as a possible upstream regulator of $\mathrm{CAPZB}$ in the setting of EpiS. We herein describe the oncogenic functions of CAPZB in EpiS, with emphasis on the association with INI1.

\section{Methods}

\section{Immunohistochemistry}

Fifteen cases of EpiS (distal type: 9 cases, proximal type: 6 cases) were chosen from among the pathological records at Juntendo University Hospital or the National cancer Center, Japan According to the World Health Organization (WHO) Classification of Tumors [20], the pathological diagnosis of EpiS for each FFPE case were made by an experienced sarcoma-based pathologist with the conventional immunohistochemical staining such as cytokeratin, EMA, CD34 and vimentin. All cases were positive for CD34, and also positive for at least either cytokeratin or EMA. Loss of INI1 expression was also confirmed for all cases. These fifteen cases of EpiS were used for immunohistochemistry for CAPZB. In brief, 4- $\mu \mathrm{m}$-thick tissue sections were cut from formalin-fixed, paraffin-embedded blocks. Following deparaffinization, the sections were autoclaved for antigen retrieval in Tris-EDTA buffer $(\mathrm{pH} 9.0)$ at $121{ }^{\circ} \mathrm{C}$ for $30 \mathrm{~min}$ and incubated with a commercial monoclonal antibody against CAPZB (dilution 1: 200,
Abcam, ab122980). Immunostaining was carried out according to the streptavidin biotin peroxidase method using a Strept ABC Complex/horseradish peroxidase kit (DAKO, Glostrup, Denmark). Because it has been shown that CAPZB generally localize at the cytoplasm or cellular membrane, we counted only cytoplasmic/membranous staining as positive staining. We uploaded files of the CAPZB immunohistochemical staining of all cases as Additional file 1: Figure S1 and Additional file 2: Figure S2.

Regarding the positive and negative controls of CAPZB IHC, lymphoid cells served as positive control and smooth muscle cells of the vessels as negative control in the immunohistochemical sections, as shown in the Human Protein Atlas homepage (http://www.proteinatlas.org/). Lymphoid cells served as positive control and smooth muscle cells as negative control.

This study was approved by the ethical review board of Juntendo University Hospital and the National Cancer Center, and signed informed consent was obtained from all of the study patients.

\section{Cell lines}

Two EpiS cell lines, VAESBJ (CRL-2138, American Type Culture Collection) and ESX (kindly provided by Sapporo Medical College, Sapporo, Japan) were used in this study. The cells were maintained in DMEM (Life Technologies, Inc., Bethesda, MD) and IMDM (Life Technologies, Inc., Bethesda, MD) supplemented with $10 \%$ FBS, respectively. The cells were incubated at $37{ }^{\circ} \mathrm{C}$ in $5 \% \mathrm{CO}_{2}$. VAESBJ cells have a deletion of the INI1 gene [8] and show the loss of the INI1 protein expression, whereas ESX cells exhibit the INI1 protein expression [21].

\section{Knockdown of CAPZB in EpiS cell lines}

The EpiS cell lines were treated with $20 \mathrm{nM}$ of two siRNAs for CAPZB (Hs_CAPZB_5777 and Hs_CAPZB_5779, Sigma-Aldrich, St. Louis, MO, USA), siRNA1 (5' -CUCG UUAGAUUCCUUUCUUTT-3', antisense 5' -AAGAA AGGAAUCUAACGAGTT-3') and siRNA2 (sense 5' -G GGAUUCCAUCCACGUGGUTT-3', antisense 5' -ACC ACGUGGAU-GGAAUCCCTT-3'), or siRNA negative control (Sigma-Aldrich, St. Louis, MO, USA) using Lipofectamine $^{\mathrm{TM}}$ RNAiMAX reagent (Invitrogen, Carlsbad, CA, USA). At $72 \mathrm{~h}$ after transfection, total protein was isolated from each cell line, and the expression level of CAPZB was validated using a Western blotting analysis.

\section{Western blotting}

The proteins were separated via SDS-PAGE and transferred to nitrocellulose membranes. The membranes were incubated with either of the following antibodies: mouse monoclonal antibodies against CAPZB (dilution 1: 1,000, Abcam, ab122980), INI1 (dilution 1: 500, BD 
Transduction Laboratories, 612110) or GAPDH (dilution 1: 500, Santa Cruz, sc-32233). After incubation, the membranes were washed three times with Tris-EDTA buffer and then reacted with horseradish peroxidaseconjugated secondary antibodies (1:1,000 dilution, GE Healthcare Biosciences).

\section{Preparation of retrovirus and transduction of the cell lines}

The Tet-On expression system was used for transduction of the genes of interest, and the TRMPV-Neo (Addgene Plasmid \#27990) vector system was used for retrovirus production (PMID: 21131983). The sh-RNA site was deleted from the TRMPV-Neo vector for the DsRed overexpression vector (TRMPV-DsRed-Neo), and SMARCB1 was subcloned from human diploid fibroblasts into the position of DsRed for TRMPV-SMARCB1-Neo. MSCVrtTA-EcoR-Puro was kindly provided by Dr. Scott Lowe. Retroviruses were obtained using 293 T cells as packaging cells, infected into the EpiS lines and selected with $4 \mu \mathrm{g} / \mathrm{ml}$ of puromycin or $500 \mu \mathrm{g} / \mathrm{ml}$ of G418 (Invitrogen, Carlsbad, CA, USA). Transcription of the TRE-regulated target gene was stimulated by rtTA in the presence of $10 \mathrm{ng} / \mathrm{ml}$ of doxycycline (Dox) (Sigma-Aldrich, St. Louis, MO, USA).

\section{Cell proliferation assay}

VAESBJ and ESX cells were seeded in 96-well plates at 2,000 cells/well and 3,000 cells/well, respectively on day 1. On day 1, transfection was performed with $20 \mathrm{nM}$ of the same siRNA reagents described above. Cell proliferation was monitored using the Cell Counting Kit-8 (Dojindo, Kumamoto, Japan) and a microplate reader to measure the absorbance of the culture medium at $450 \mathrm{~nm}$ according to the manufacturer's instruction manual. All proliferation experiments were performed in triplicate, and the results were averaged.

\section{Invasion assay}

The invasion assays were performed using 24-well BD BioCoat Matrigel Invasion Chambers (BD Biosciences, Franklin Lakes, NY), according to the manufacturer's protocol. VAESBJ and ESX cell suspensions were prepared at a density of $8 \times 10^{4}$ cells $/ \mathrm{mL}$ and $3 \times 10^{5}$ cells $/ \mathrm{mL}$ in $0.5-\mathrm{ml}$ serum-free medium and added to the gel chamber insert. After $48 \mathrm{~h}$ of incubation, noninvading cells were removed with cotton swabs, and invading cells were stained using Diff-Quick reagent (Sysmex, Kobe, Hyogo, Japan). The number of invading cells was counted, and the invasion index was calculated as the percent invasion of transfected cells/ non-transfected cells.

\section{Scratch assay}

The rate of cell migration was assessed using a scratch assay. The VAESBJ cell line transfected with CAPZB siRNA was seeded on a 6-well plate and allowed to reach confluence. After scratching the bottom of the well with a pipette tip, the monolayer of cells was washed with PBS to remove detached cells. The remaining adherent cells were incubated in medium containing $0.2 \% \mathrm{FBS}$, and the area of the scratch wound was evaluated at $48 \mathrm{~h}$ after transfection. The experiments were performed in triplicate.

Proteomic analysis using iTRAQ (isobaric tags for relative and absolute quantification) and mass spectrometry

Isobaric tags for relative and absolute quantification (iTRAQ), a form of chemical labeling mass spectrometry, were created according to the company's protocol [22]. Briefly, the cell lysate was extracted from each cell and subjected to a LC-shot gun analysis using the iTRAQ method, as previously described [23]. Prior to the iTRAQ analysis, the lysate samples were concentrated and buffer exchanged using a $3.5-\mathrm{kDa}$ molecular weight cut-off spin concentrator (TOMY SEIKO CO., LTD, Tokyo, Japan) then digested for $24 \mathrm{~h}$ with $10 \mu \mathrm{g}$ of L-1-(4-tosylamido)-2-phenylethyl tosyl phenylalanyl chloromethyl ketone (TPCK)-treated trypsin. Each peptide solution was labelled with one of the four iTRAQ reagents (iTRAQ reporter ions of 114, 115, 116 and 117 mass/charge ratio) according to the manufacturer's protocol (AB SCIEX, Framingham, MA, USA). The labelled peptides were pooled and fractionated via strong cation exchange (SCX) using a ChromXP C18-CL column (Eksigent parts of AB SCIEX, Dublin, California, USA) and analyzed with nano LC-MS/MS [24]; nano LC-MS/MS was performed using a TripleTOF ${ }^{\odot} 5600$ mass spectrometer for MS/MS (AB SCIEX) interfaced with a nano LC system (Eksigent parts of AB SCIEX).

\section{Peptide identification}

Protein identification and relative quantification were carried out as previously described (ProteinPilot ${ }^{\mathrm{Tm}}$ Software Version 4.5) [25]. Functional definitions of the variable protein contents were searched against the Swissport database (Release, 6/20/2014) using the search algorithm contained within the ProteinPilot ${ }^{\mathrm{TM}}$ Software and Analyst ${ }^{\oplus}$ TF Software programs (AB SCIEX). The protein ratios were normalized using the overall median ratio for all peptides in the sample for the separate ratios in each individual experiment. A confidence cutoff value for protein identification of $>95 \%$ was applied for protein identification, and a $>1.2$-fold change cutoff was selected for all of the iTRAQ ratios in order to classify proteins as upregulated or downregulated as previously described [26]. 


\section{Pathway analysis}

The Ingenuity Pathways Analysis (IPA) (Ingenuity Systems, Redwood City, CA) software program was further used to determine the functional pathways represented by the identified genes. The IPA software package contains a database of biological interactions among genes and proteins, which was used to calculate the probability of a relationship between each canonical pathway, upstream pathway and the identified proteins. The IPA program scans the set of input proteins to identify networks using the Ingenuity Pathway Knowledge Base (IPKB) for interactions between identified proteins and known and hypothetical interacting genes stored in the IPA software database.

\section{Statistical Analysis}

Data from the western blotting and quantitative-PCR were analyzed using the t-test. The significance of differences in the functional assays of EpiS cell lines following transfection was evaluated using the t-test.

The statistical analysis of protein expression profiles is based on $p$-value and threshold using Protein Pilot version 4.5 software (AB SCIEX) [27].

\section{Results}

CAPZB expression in EpiS clinical samples and EpiS cells

Fifteen cases of EpiS were examined using immunohistochemistry to confirm the protein expression and localization of CAPZB. In all 15 cases, more than $70 \sim 80 \%$ of tumor cells were positive for CAPZB and CAPZB was localized in the cytoplasm. Some cases also showed nuclear staining (Fig. 1a, Additional file 1: Figure S1 and Additional file 2: Figure S2). These results were consistent with the findings of our previous proteomic analysis showing that tumor tissues of ES have higher CAPZB expression levels than normal tissues [9]. In the present study, we also confirmed the expressions of CAPZB in the two EpiS cell lines (VAESBJ and ESX cells) using WB (Fig. 1b).

\section{Functional analysis of CAPZB}

In order to investigate the cellular functions of $\mathrm{CAPZB}$ in EpiS, we performed siRNA assays of CAPZB using the two EpiS cell lines. As a result, treatment with two siRNAs (si-CAPZB-1 and si-CAPZB-2) significantly decreased the expression levels of CAPZB compared to that observed in the control cells for both the VAESBJ and ESX cells (Fig. 1b). Following gene silencing of CAPZB by the two siRNAs in both EpiS cell lines, we performed in vitro assays consisting of cell proliferation, invasion and scratch assays. In the cell proliferation assays, knockdown of CAPZB significantly decreased the rate of cell growth at $96 \mathrm{~h}$ after transfection in both the VAESBJ and ESX cells (Fig. 2a). In the invasion assays, the CAPZB-silenced cells demonstrated markedly

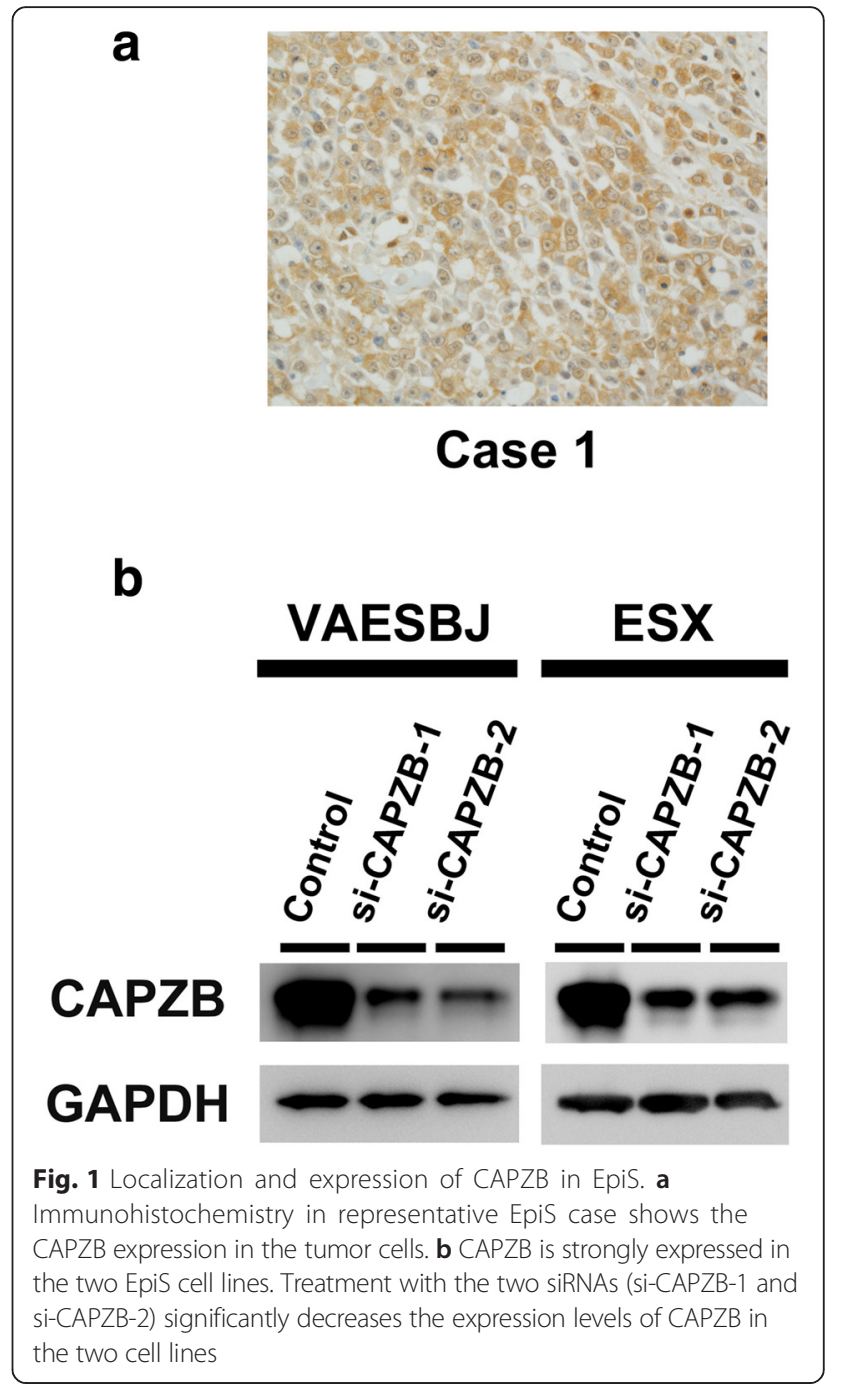

decreased cell invasion (Fig. 2b). In the scratch assays, silencing of CAPZB in the VAESBJ cells significantly suppressed cell migration compared to that observed in the control cells (Fig. 2c). We were unable to obtain cell migration data for the ESX cells because these cells easily detached from the culture plate with scratching.

Next, we performed a proteomics approach using i-TRAQ assays with the CAPZB siRNA-transfected EpiS cells in order to determine the differences in the protein expression profile according to the knockdown of CAPZB in EpiS. Consequently, the protein expression profiles differed significantly between the CAPZB-silenced cells and the control cells $(p<0.05)$. This analysis revealed protein profiles consisting of 26 downregulated proteins and 39 upregulated proteins in the VAESBJ cells $(p<0.05$, Table 1), as well as 69 downregulated proteins and 41 upregulated proteins in the ESX cells $(p<0.05$, Table 2$)$. The numbers of commonly upregulated and downregulated proteins between two cell lines were 3 and 8 , 
a

\section{VAESBJ}

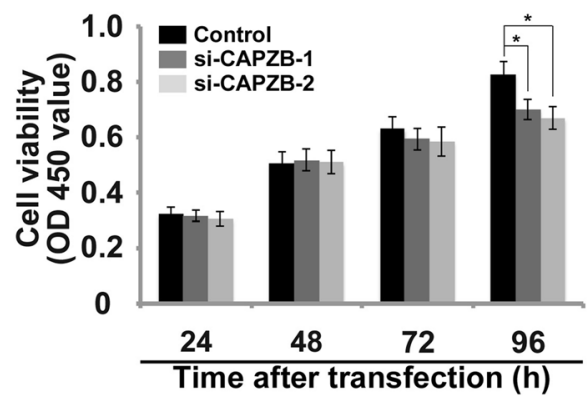

b

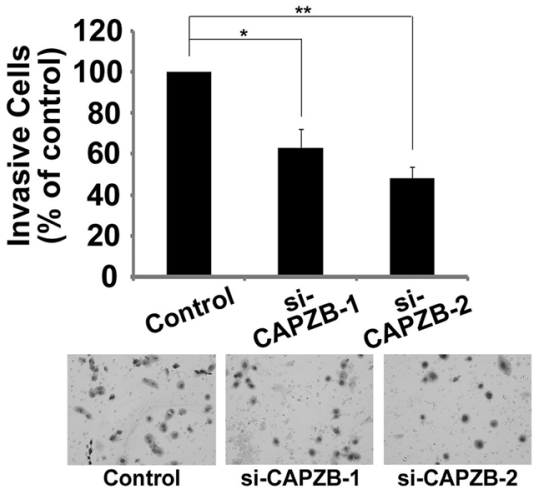

ESX

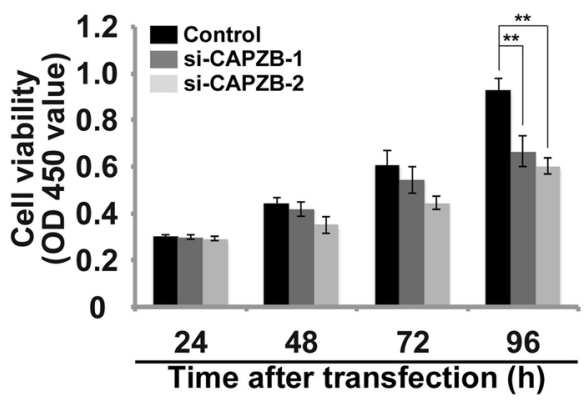

ESX

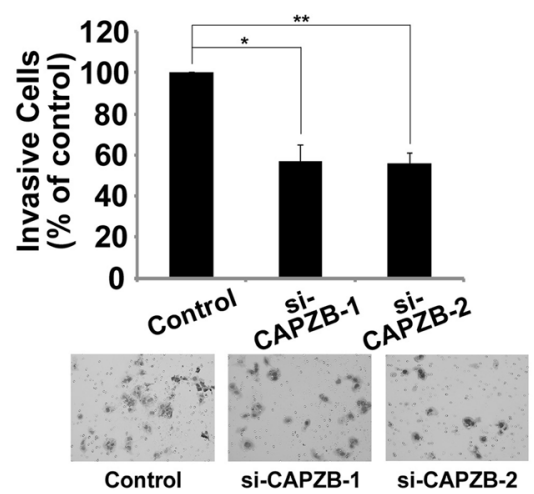

C

VAESBJ
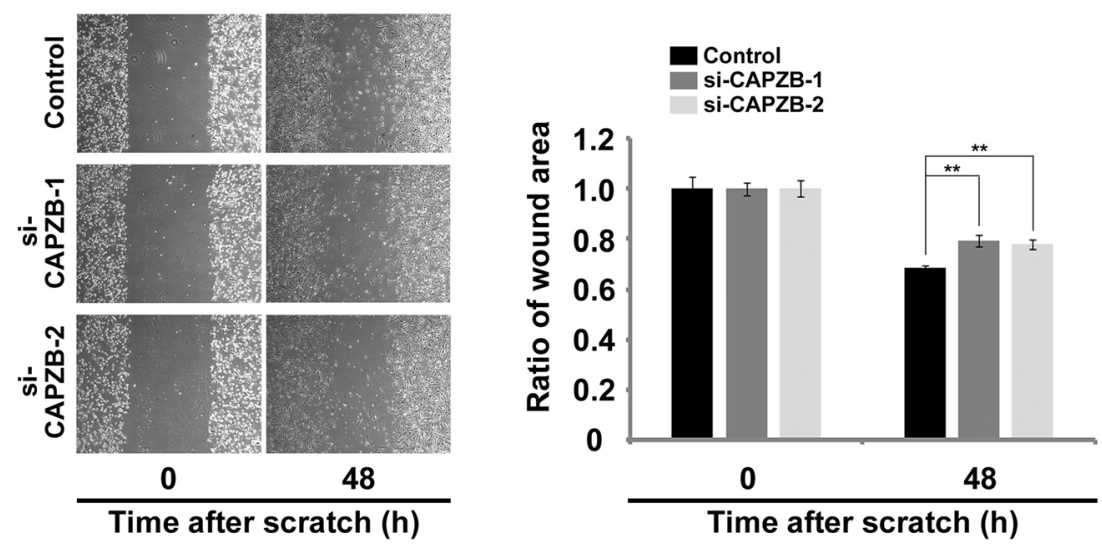

Fig. 2 Progressive effect of CAPZB in EpiS cellular function. a In the proliferation assays, si-CAPZB-1 and si-CAPZB-2 inhibited cell growth by $85 \%$ and $81 \%$ in the VAESBJ cells and $71 \%$ and $65 \%$ in the ESX cells, respectively $(p<0.01, p<0.05$, Figure $2 B$ left and right, respectively). $\mathbf{b}$ In the invasion assays, si-CAPZB-1 and si-CAPZB-2 decreased cell invasion by $63 \%$ and $48 \%$ in the VAESBJ cells and $57 \%$ and $56 \%$ in the ESX cells, respectively $(p<0.01, p<0.05$, Figure $2 \mathrm{c}$ left and right, respectively). $\mathbf{c}$ In the scratch assays, CAPZB silencing suppressed the area of wound healing in the VAESBJ cells ( $p<0.01$, Control: $32 \%$, si-CAPZB-1: $21 \%$, si-CAPZB- 2 : $22 \%$, Fig. $2 d$ )

respectively. In order to further understand the biological networks associated with CAPZB, we employed a network analysis using the IPA system with the above obtained protein profiles in the VAESBJ and ESX cells. The results of the IPA analyses are shown in Additional file 1: Figure S1, Additional file 2: Figure S2, Additional file 3: Table S1 and Additional file 4: Table S2. These results pointed to several SWI/SNF chromatin- 
Table 1 Protein profiles of CAPZB-regulated proteins in the VAESBJ cells

\begin{tabular}{|c|c|c|c|c|}
\hline${ }^{\mathrm{a} A c c e s s i o n}$ no. & Symbol & Protein name & Fold difference & $P$ value \\
\hline P07355 & ANXA2 & Annexin A2 & 1.90 & $0.00 \mathrm{E}+00$ \\
\hline P02768 & ALBU & Serum albumin & 1.85 & 2.17E-02 \\
\hline P08195 & $4 \mathrm{~F} 2$ & Isoform 3 of 4 F2 cell-surface antigen heavy chain & 1.63 & 1.00E-04 \\
\hline Q16222 & UAP1 & UDP-N-acetylhexosamine pyrophosphorylase & 1.55 & $3.10 \mathrm{E}-03$ \\
\hline Q09666 & AHNK & Neuroblast differentiation-associated protein AHNAK & 1.53 & $0.00 E+00$ \\
\hline P08243 & ASNS & Asparagine synthetase [glutamine-hydrolyzing] & 1.45 & 2.00E-04 \\
\hline Q96HC4 & PDLI5 & PDZ and LIM domain protein 5 & 1.44 & 1.37E-02 \\
\hline P13797 & PLST & Plastin-3 & 1.44 & $0.00 \mathrm{E}+00$ \\
\hline P21589 & $5 N T D$ & 5'-nucleotidase & 1.43 & $5.10 \mathrm{E}-03$ \\
\hline P15144 & AMPN & Aminopeptidase $N$ & 1.42 & $1.00 \mathrm{E}-03$ \\
\hline P26639 & SYTC & Threonine-tRNA ligase, cytoplasmic & 1.39 & 2.00E-04 \\
\hline Q05682 & CALD1 & Isoform 5 of Caldesmon & 1.38 & 3.20E-03 \\
\hline P06756 & ITAV & Integrin alpha-V & 1.33 & $2.14 \mathrm{E}-02$ \\
\hline P21333 & FLNA & Isoform 2 of Filamin-A & 1.32 & $0.00 E+00$ \\
\hline P05556 & ITB1 & Integrin beta-1 & 1.32 & $0.00 E+00$ \\
\hline P18206 & VINC & Vinculin & 1.31 & $0.00 E+00$ \\
\hline P06737 & PYGL & Glycogen phosphorylase, liver form & 1.30 & 1.13E-02 \\
\hline O43175 & SERA & D-3-phosphoglycerate dehydrogenase & 1.30 & 1.27E-02 \\
\hline P00390 & GSHR & Glutathione reductase, mitochondrial & 1.29 & $3.08 \mathrm{E}-02$ \\
\hline P16989 & YB0X3 & Y-box-binding protein 3 & 1.29 & $3.19 \mathrm{E}-02$ \\
\hline Q9UKK3 & PARP4 & Poly [ADP-ribose] polymerase 4 & 1.29 & 4.22E-02 \\
\hline Q9Y617 & SERC & Phosphoserine aminotransferase & 1.28 & $1.80 \mathrm{E}-02$ \\
\hline P06733 & ENOA & Alpha-enolase & 1.26 & $1.00 \mathrm{E}-03$ \\
\hline P00352 & $\mathrm{AL} 1 \mathrm{~A} 1$ & Retinal dehydrogenase 1 & 1.26 & $1.00 \mathrm{E}-04$ \\
\hline P49591 & SYSC & Serine_-tRNA ligase, cytoplasmic & 1.24 & $9.70 \mathrm{E}-03$ \\
\hline P20810 & ICAL & Isoform 9 of Calpastatin & 1.23 & 2.19E-02 \\
\hline P41250 & SYG & Glycine-tRNA ligase & 1.23 & $2.51 \mathrm{E}-02$ \\
\hline O60884 & DNJA2 & DnaJ homolog subfamily A member 2 & 1.21 & 2.44E-02 \\
\hline Q9NSE4 & SYIM & Isoleucine_-tRNA ligase, mitochondrial & 1.21 & 2.46E-02 \\
\hline P61289 & PSME3 & Proteasome activator complex subunit 3 & 1.21 & $1.26 \mathrm{E}-02$ \\
\hline P27824 & CALX & Calnexin & 1.20 & $1.24 \mathrm{E}-02$ \\
\hline P15311 & EZRI & Ezrin & 1.20 & 2.00E-04 \\
\hline Q9BXJ9 & NAA15 & N-alpha-acetyltransferase 15, NatA auxiliary subunit & 1.19 & $3.35 \mathrm{E}-02$ \\
\hline P43490 & NAMPT & Nicotinamide phosphoribosyltransferase & 1.18 & $1.59 \mathrm{E}-02$ \\
\hline Q01813 & K6PP & 6-phosphofructokinase type $C$ & 1.18 & 2.47E-02 \\
\hline O75369 & FLNB & Isoform 2 of Filamin-B & 1.16 & $6.00 \mathrm{E}-04$ \\
\hline P22102 & PUR2 & Trifunctional purine biosynthetic protein adenosine-3 & 1.15 & $5.80 \mathrm{E}-03$ \\
\hline P49411 & EFTU & Elongation factor Tu, mitochondrial & 1.10 & 1.77E-02 \\
\hline P38646 & GRP75 & Stress-70 protein, mitochondrial & 1.10 & 4.13E-02 \\
\hline Q00610 & CLH1 & Clathrin heavy chain 1 & 0.91 & 4.92E-02 \\
\hline P13010 & XRCC5 & X-ray repair cross-complementing protein 5 & 0.90 & 2.90E-02 \\
\hline P25685 & DNJB1 & DnaJ homolog subfamily B member 1 & 0.85 & $1.49 \mathrm{E}-02$ \\
\hline P61981 & $1433 G$ & 14-3-3 protein gamma & 0.85 & 2.42E-02 \\
\hline P30086 & PEBP1 & Phosphatidylethanolamine-binding protein 1 & 0.84 & $1.79 \mathrm{E}-02$ \\
\hline
\end{tabular}


Table 1 Protein profiles of CAPZB-regulated proteins in the VAESBJ cells (Continued)

\begin{tabular}{|c|c|c|c|c|}
\hline P09382 & LEG1 & Galectin-1 & 0.84 & $3.48 \mathrm{E}-02$ \\
\hline P08133 & ANXA6 & Annexin A6 & 0.84 & 2.00E-04 \\
\hline 043747 & AP1G1 & Isoform 2 of AP-1 complex subunit gamma-1 & 0.83 & 2.44E-02 \\
\hline P05787 & $\mathrm{K} 2 \mathrm{C} 8$ & Keratin, type II cytoskeletal 8 & 0.82 & 4.00E-04 \\
\hline P10644 & KAPO & CAMP-dependent protein kinase type I-alpha regulatory subunit & 0.81 & 4.19E-02 \\
\hline Q9NZ01 & TECR & Very-long-chain enoyl-CoA reductase & 0.81 & 4.10E-02 \\
\hline Q9BUJ2 & HNRL1 & Heterogeneous nuclear ribonucleoprotein U-like protein 1 & 0.81 & $3.70 \mathrm{E}-02$ \\
\hline 014579 & COPE & Coatomer subunit epsilon & 0.80 & 4.18E-02 \\
\hline P08727 & $\mathrm{K} 1 \mathrm{C} 19$ & Keratin, type I cytoskeletal 19 & 0.79 & 4.10E-03 \\
\hline P07108 & ACBP & Isoform 3 of Acyl-CoA-binding protein & 0.79 & $2.54 \mathrm{E}-02$ \\
\hline P63104 & $1433 Z$ & 14-3-3 protein zeta/delta & 0.78 & $1.61 \mathrm{E}-02$ \\
\hline Q15274 & NADC & Nicotinate-nucleotide pyrophosphorylase [carboxylating] & 0.78 & 4.40E-02 \\
\hline P25705 & ATPA & ATP synthase subunit alpha, mitochondrial & 0.77 & $1.82 \mathrm{E}-02$ \\
\hline P04080 & CYTB & Cystatin-B & 0.77 & $1.03 \mathrm{E}-02$ \\
\hline P53634 & CATC & Dipeptidyl peptidase 1 & 0.77 & 3.85E-02 \\
\hline Q07955 & SRSF1 & Serine/arginine-rich splicing factor 1 & 0.76 & 1.99E-02 \\
\hline Q9NQC3 & RTN4 & Isoform 2 of Reticulon-4 & 0.71 & $2.76 \mathrm{E}-02$ \\
\hline P00568 & KAD1 & Adenylate kinase isoenzyme 1 & 0.70 & 5.10E-03 \\
\hline Q7L1QB & BZW1 & Basic leucine zipper and W2 domain-containing protein 1 & 0.65 & 1.10E-03 \\
\hline Q9ULV4 & COR1C & Isoform 3 of Coronin-1C & 0.63 & 2.10E-03 \\
\hline P52907 & CAZA1 & F-actin-capping protein subunit alpha-1 & 0.62 & $1.71 \mathrm{E}-02$ \\
\hline P04264 & $\mathrm{K} 2 \mathrm{C} 1$ & Keratin, type II cytoskeletal 1 & 0.39 & 2.00E-04 \\
\hline P04179 & SODM & Superoxide dismutase $[\mathrm{Mn}]$, mitochondrial & 0.34 & 3.08E-02 \\
\hline P35527 & $\mathrm{K} 1 \mathrm{C} 9$ & Keratin, type I cytoskeletal 9 & 0.29 & 4.20E-03 \\
\hline
\end{tabular}

${ }^{a}$ Accession numbers of proteins were derived from Swiss-Plot data base

remodeling complexes as possible upstream regulators or critical pathways among the identified network lists. We also found INI1 to be included in the identified SWI/SNF chromatin-remodeling complex list (Additional file 3: Table S1 and Additional file 4: Table S2).

In order to elucidate the possible association between the INI1 and CAPZB expression, we performed siRNA assays of CAPZB in the two EpiS cell lines and measured the expression levels of CAPZB and INI1 using WB. In the ESX cell line (without the loss of INI1), gene silencing of CAPZB led to a decrease in the expression level of INI1 (Fig. 3, right). In the VAESBJ cell line (with the loss of INI1), the INI1 expression remained lost (Fig. 3, left).

Next, we attempted to assess the effects of INI1 overexpression in the VAESBJ and ESX cells. These EpiS cell lines were stably transfected with either Dox-inducible empty (RFP) or the INI1 expression vector, and the expression levels of INI1 were confirmed with WB. In the VAESBJ cell line, in which INI1 was lost, Dox induction in the INI1-transfected cells (INI1+) induced the INI1 expression (Fig. 4a, upper left). In the ESX cell line, Dox induction in the INI1-transfected ESX cells resulted in a higher expression of INI1 than that noted in the other three cell lines (Fig. 4a, upper right). According to the presence of INI1 induction, a real-time PCR assay revealed that the expression level of CAPZB in the Doxinduced INI1-transfected cells was significantly higher than that observed in the other three cells among the VAESBJ cells (Fig. 4c). However, the WB assay did not detect apparent differences in the CAPZB expression (Fig. 4a, middle). Based on these findings, it was difficult to assume the direct effect of INI1 on CAPZB in EpiS cells. Regarding the proliferation of the Dox-induced INI1-overexpressing cells, the cell growth of the Doxinduced INI1-overexpressing VAESBJ cells was markedly suppressed compared to that of the control cells (Fig. 4b, left). However, the Dox-induced INI1-overexpression in VAESBJ cells did not affect the migration and invasion properties (Data not shown). In contrast, in the ESX cell lines, Dox-induced INI1-overexpression did not affect cell proliferation (Fig. 4b, right).

\section{Discussion}

Capping proteins are known to increase actin filament depolymerization and promote cell motility $[10,11]$. 
Table 2 Protein profiles of CAPZB-regulated proteins in the ESX cells

\begin{tabular}{|c|c|c|c|c|}
\hline${ }^{\mathrm{a}}$ Accession no. & Symbol & Name & Fold difference & $P$ value \\
\hline Q15738 & NSDHL & Sterol-4-alpha-carboxylate 3-dehydrogenase, decarboxylating & 2.02 & $2.50 \mathrm{E}-03$ \\
\hline Q9P287 & BCCIP & BRCA2 and CDKN1 A-interacting protein & 2.02 & $3.48 \mathrm{E}-02$ \\
\hline Q9NZL4 & HPBP1 & Hsp70-binding protein 1 & 1.90 & $2.65 \mathrm{E}-02$ \\
\hline P14174 & MIF & Macrophage migration inhibitory factor & 1.84 & 3.30E-02 \\
\hline P20591 & $M \times 1$ & Interferon-induced GTP-binding protein Mx1 & 1.82 & 2.64E-02 \\
\hline P20936 & RASA1 & Ras GTPase-activating protein 1 & 1.76 & 4.03E-02 \\
\hline O95373 & IP07 & Importin-7 & 1.73 & 7.70E-03 \\
\hline P27144 & KAD4 & Adenylate kinase 4, mitochondrial & 1.67 & 1.44E-02 \\
\hline Q96EK5 & KBP & KIF1—binding protein & 1.65 & $1.70 \mathrm{E}-02$ \\
\hline Q9P2J5 & SYLC & Leucine-tRNA ligase, cytoplasmic & 1.64 & 1.17E-02 \\
\hline P49354 & FNTA & Protein farnesyltransferase/geranylgeranyltransferase type-1 subunit alpha & 1.63 & 7.40E-03 \\
\hline P25786 & PSA1 & Proteasome subunit alpha type-1 & 1.58 & $3.89 \mathrm{E}-02$ \\
\hline P49773 & HINT1 & Histidine triad nucleotide-binding protein 1 & 1.52 & $7.20 \mathrm{E}-03$ \\
\hline P51003 & PAPOA & Poly(A) polymerase alpha & 1.51 & 2.49E-02 \\
\hline P09211 & GSTP1 & Glutathione S-transferase P & 1.50 & 4.95E-02 \\
\hline P07339 & CATD & Cathepsin D & 1.50 & $2.52 \mathrm{E}-02$ \\
\hline P12277 & KCRB & Creatine kinase B-type & 1.46 & 4.14E-02 \\
\hline P61289 & PSME3 & Proteasome activator complex subunit 3 & 1.44 & 4.77E-02 \\
\hline Q4J6C6 & PPCEL & Prolyl endopeptidase-like & 1.43 & 4.89E-02 \\
\hline Q6IBS0 & TWF2 & Twinfilin-2 & 1.43 & 4.96E-02 \\
\hline P14625 & ENPL & Endoplasmin & 1.42 & $0.00 \mathrm{E}+00$ \\
\hline P55060 & XP02 & Exportin-2 & 1.42 & 1.30E-03 \\
\hline P08238 & HS90B & Heat shock protein HSP 90-beta & 1.39 & 4.10E-02 \\
\hline P30041 & PRDX6 & Peroxiredoxin-6 & 1.38 & $1.02 \mathrm{E}-02$ \\
\hline 000410 & IP05 & Isoform 3 of Importin-5 & 1.37 & 2.24E-02 \\
\hline Q14697 & GANAB & Neutral alpha-glucosidase $A B$ & 1.36 & 2.03E-02 \\
\hline P13797 & PLST & Plastin-3 & 1.36 & $5.50 \mathrm{E}-03$ \\
\hline 043681 & ASNA & ATPase ASNA1 & 1.32 & 3.37E-02 \\
\hline P27824 & CALX & Calnexin & 1.31 & 3.94E-02 \\
\hline P48735 & IDHP & Isocitrate dehydrogenase [NADP], mitochondrial & 1.30 & 4.29E-02 \\
\hline P50395 & GDIB & Rab GDP dissociation inhibitor beta & 1.30 & $2.38 \mathrm{E}-02$ \\
\hline O60488 & ACSL4 & Long-chain-fatty-acid_CoA ligase 4 & 1.29 & $1.79 \mathrm{E}-02$ \\
\hline P80303 & NUCB2 & Nucleobindin-2 & 1.29 & $2.91 \mathrm{E}-02$ \\
\hline P05455 & $\mathrm{LA}$ & Lupus La protein & 1.27 & 2.40E-02 \\
\hline Q15084 & PDIA6 & Protein disulfide-isomerase A6 & 1.26 & 4.60E-03 \\
\hline Q16576 & RBBP7 & Histone-binding protein RBBP7 & 1.25 & 4.35E-02 \\
\hline Q99832 & $\mathrm{TCPH}$ & T-complex protein 1 subunit eta & 1.24 & 4.78E-02 \\
\hline P50990 & TCPQ & T-complex protein 1 subunit theta & 1.21 & $9.70 \mathrm{E}-03$ \\
\hline P10809 & $\mathrm{CH} 60$ & $60 \mathrm{kDa}$ heat shock protein, mitochondrial & 1.18 & 4.64E-02 \\
\hline Q06830 & PRDX1 & Peroxiredoxin-1 & 1.18 & 2.23E-02 \\
\hline P50502 & F10A1 & Hsc70-interacting protein & 1.15 & 1.39E-02 \\
\hline O75369 & FLNB & Isoform 2 of Filamin-B & 0.85 & 1.33E-02 \\
\hline P12814 & ACTN1 & Isoform 3 of Alpha-actinin-1 & 0.84 & $3.51 \mathrm{E}-02$ \\
\hline P35580 & MYH10 & Myosin-10 & 0.84 & 1.10E-03 \\
\hline
\end{tabular}


Table 2 Protein profiles of CAPZB-regulated proteins in the ESX cells (Continued)

\begin{tabular}{|c|c|c|c|c|}
\hline P09496 & CLCA & Clathrin light chain A & 0.84 & 4.71 E-02 \\
\hline P21333 & FLNA & Isoform 2 of Filamin-A & 0.84 & $5.00 \mathrm{E}-04$ \\
\hline P26583 & HMGB2 & High mobility group protein B2 & 0.83 & 1.86E-02 \\
\hline O60841 & IF2P & Eukaryotic translation initiation factor $5 \mathrm{~B}$ & 0.83 & $3.66 \mathrm{E}-02$ \\
\hline Q08257 & QOR & Quinone oxidoreductase & 0.83 & 2.95E-02 \\
\hline Q9Y3A5 & SBDS & Ribosome maturation protein SBDS & 0.82 & 4.20E-02 \\
\hline Q14203 & DCTN1 & Dynactin subunit 1 & 0.81 & 4.67E-02 \\
\hline Q00839 & HNRPU & Heterogeneous nuclear ribonucleoprotein $U$ & 0.81 & 2.61 E-02 \\
\hline O15371 & EIF3D & Eukaryotic translation initiation factor 3 subunit D & 0.79 & 4.68E-02 \\
\hline Q6UB35 & C1TM & Monofunctional C1 tetrahydrofolate synthase, mitochondrial & 0.79 & 3.39E-02 \\
\hline P39019 & RS19 & $40 S$ ribosomal protein S19 & 0.77 & $1.28 \mathrm{E}-02$ \\
\hline P27816 & MAP4 & Isoform 6 of Microtubule-associated protein 4 & 0.77 & 4.66E-02 \\
\hline Q00688 & FKBP3 & Peptidyl-prolyl cis-trans isomerase FKBP3 & 0.77 & $3.16 \mathrm{E}-02$ \\
\hline Q9BUJ2 & HNRL1 & Heterogeneous nuclear ribonucleoprotein $\mathrm{U}$ —like protein 1 & 0.76 & 1.06E-02 \\
\hline P08195 & $4 \mathrm{~F} 2$ & Isoform 3 of 4 F2 cell-surface antigen heavy chain & 0.76 & 2.10E-02 \\
\hline P52272 & HNRPM & Heterogeneous nuclear ribonucleoprotein M & 0.70 & $2.82 \mathrm{E}-02$ \\
\hline Q15274 & NADC & Nicotinate-nucleotide pyrophosphorylase [carboxylating] & 0.76 & $3.26 \mathrm{E}-02$ \\
\hline Q12906 & ILF3 & Interleukin enhancer-binding factor 3 & 0.70 & 2.04E-02 \\
\hline P08670 & VIME & Vimentin & 0.75 & $1.00 \mathrm{E}-04$ \\
\hline P18124 & RL7 & OOS ribosomal protein $\mathrm{L} 7$ & 0.74 & 1.15E-02 \\
\hline Q92841 & DDX17 & Isoform 4 of Probable ATP-dependent RNA helicase DDX17 & 0.74 & $5.60 \mathrm{E}-03$ \\
\hline P62906 & RL10A & $80 S$ ribosomal protein L10a & 0.73 & 2.09E-02 \\
\hline P16989 & YBOX3 & Y-box-binding protein 3 & 0.73 & $1.50 \mathrm{E}-02$ \\
\hline P05161 & ISG15 & Ubiquitin—like protein ISG15 & 0.73 & 2.87E-02 \\
\hline P06748 & NPM & Nucleophosmin & 0.72 & 1.07E-02 \\
\hline O00571 & DDX3X & ATP-dependent RNA helicase DDX3X & 0.71 & 7.00E-03 \\
\hline P62424 & RL7A & $80 S$ ribosomal protein $\mathrm{L} 7 \mathrm{a}$ & 0.71 & 3.87E-02 \\
\hline P46776 & RL27A & $60 S$ ribosomal protein $\mathrm{L} 27 \mathrm{a}$ & 0.71 & 3.40E-02 \\
\hline P83881 & RL30A & 605 ribosomal protein L36a & 0.70 & 2.03E-02 \\
\hline P46777 & RL5 & 605 ribosomal protein $\mathrm{L} 5$ & 0.70 & $2.00 \mathrm{E}-04$ \\
\hline P62913 & RL11 & 605 ribosomal protein L11 & 0.70 & $1.04 \mathrm{E}-02$ \\
\hline P50914 & RL14 & $60 S$ ribosomal protein L14 & 0.70 & $2.61 \mathrm{E}-02$ \\
\hline P62280 & RS11 & $40 S$ ribosomal protein $S 11$ & 0.70 & 1.18E-02 \\
\hline P62917 & RL8 & 605 ribosomal protein L8 & 0.70 & 5.00E-03 \\
\hline P84098 & RL19 & 605 ribosomal protein L19 & 0.69 & 1.27E-02 \\
\hline P62241 & RS8 & 405 ribosomal protein 58 & 0.69 & 2.37E-02 \\
\hline P63220 & RS21 & 40 S ribosomal protein S21 & 0.69 & $1.24 \mathrm{E}-02$ \\
\hline Q05682 & CALD1 & Isoform 5 of Caldesmon & 0.69 & $1.00 \mathrm{E}-04$ \\
\hline P54886 & P5CS & Delta-1 -pyrroline-5-carboxylate synthase & 0.68 & 1.10E-03 \\
\hline P01247 & RS3A & 405 ribosomal protein S3a & 0.68 & 7.00E-04 \\
\hline P35613 & BASI & Isoform 2 of Basigin & 0.68 & 2.83E-02 \\
\hline P26373 & RL13 & 605 ribosomal protein L13 & 0.68 & 2.19E-02 \\
\hline Q14789 & GOGB1 & Golgin subfamily B member 1 & 0.67 & $2.56 \mathrm{E}-02$ \\
\hline P05023 & AT1A1 & Sodium/potassium-transporting ATPase subunit alpha-1 & 0.67 & 2.00E-04 \\
\hline P52907 & CAZA1 & F-actin-capping protein subunit alpha-1 & 0.66 & $2.86 \mathrm{E}-02$ \\
\hline
\end{tabular}


Table 2 Protein profiles of CAPZB-regulated proteins in the ESX cells (Continued)

\begin{tabular}{|c|c|c|c|c|}
\hline P09382 & LEG1 & Galectin-1 & 0.66 & 1.40E-02 \\
\hline P09874 & PARP1 & Poly [ADP-ribose] polymerase 1 & 0.66 & 2.00E-04 \\
\hline P62750 & RL23A & $60 S$ ribosomal protein L23a & 0.66 & 4.00E-04 \\
\hline Q8NC51 & PAIRB & Plasminogen activator inhibitor 1 RNA-binding protein & 0.65 & 1.00E-04 \\
\hline P46779 & RL28 & 605 ribosomal protein L28 & 0.65 & 1.13E-02 \\
\hline P49748 & ACADV & Very long-chain specific acyl-CoA dehydrogenase, mitochondrial & 0.65 & $1.74 \mathrm{E}-02$ \\
\hline Q01082 & SPTB2 & Spectrin beta chain, non-erythrocytic 1 & 0.64 & $0.00 \mathrm{E}+00$ \\
\hline Q07955 & SRSF1 & Serine/arginine-rich splicing factor 1 & 0.64 & 3.94E-02 \\
\hline Q9NZI8 & IF2B1 & Insulin-like growth factor 2 mRNA-binding protein 1 & 0.63 & 4.10E-03 \\
\hline Q02878 & RL6 & 605 ribosomal protein L6 & 0.62 & 2.90E-03 \\
\hline Q15233 & NONO & Non-POU domain-containing octamer-binding protein & 0.62 & 2.64E-02 \\
\hline P07910 & HNRPC & Heterogeneous nuclear ribonucleoproteins C1/C2 & 0.61 & $0.00 \mathrm{E}+00$ \\
\hline P08133 & ANXA6 & Annexin A6 & 0.60 & $0.00 \mathrm{E}+00$ \\
\hline Q07020 & RL18 & 605 ribosomal protein L18 & 0.60 & $1.00 \mathrm{E}-02$ \\
\hline Q7L1Q6 & BZW1 & Basic leucine zipper and W2 domain-containing protein 1 & 0.59 & 1.00E-04 \\
\hline Q16643 & DREB & Drebrin & 0.58 & $1.00 \mathrm{E}-04$ \\
\hline Q9ULV4 & COR1C & Isoform 3 of Coronin-1C & 0.57 & 6.30E-03 \\
\hline P47756 & CAPZB & Isoform 2 of F-actin-capping protein subunit beta & 0.55 & $3.01 \mathrm{E}-02$ \\
\hline 043707 & ACTN4 & Alpha-actinin-4 & 0.54 & $0.00 \mathrm{E}+00$ \\
\hline P16070 & CD44 & Isoform 11 of CD44 antigen & 0.54 & 3.10E-03 \\
\hline P22626 & $\mathrm{ROA} 2$ & Heterogeneous nuclear ribonucleoproteins A2/B1 & 0.52 & 2.12E-02 \\
\hline
\end{tabular}

${ }^{a}$ Accession numbers of proteins were derived from Swiss-Plot data base

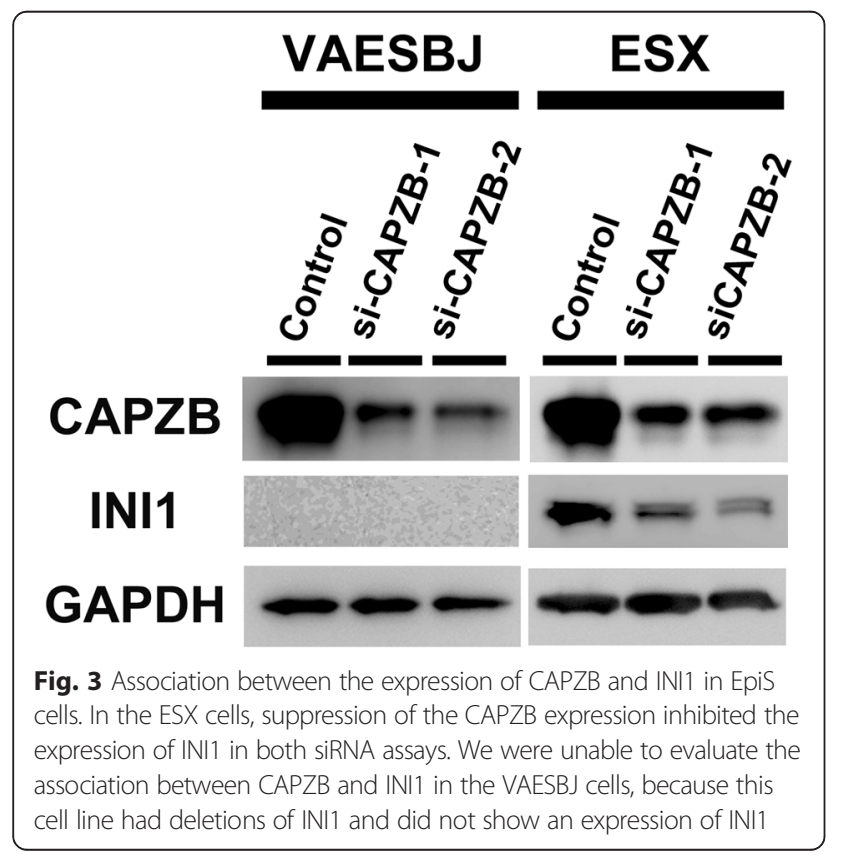

However, the associations between the expression levels of capping proteins, including CAPZB, and cancer phenotypes remain unknown. Furthermore, although we have previously reported high CAPZB expression in the tumor tissues of EpiS [9], relative expression of CAPZB in EpiS compared to other types of tumors is unknown, therefore it is difficult to refer to the association between the relative expression level of CAPZB and aggressive behavior of the tumors. Recently, CAPZA1, a member of the capping protein family, was reported to have prognostic value and a suppressive effect on cell migration and invasion in gastric cancer tissue [28], whereas the overexpression of actin-capping proteins has been shown to modulate cell motility in vitro, suggesting their potentially important role in promoting cell motility in the setting of pancreatic cancer [29]. These findings indicate that members of the capping protein family, including $\mathrm{CAPZB}$, contribute to tumor progression in several cancers in a tumor-specific manner. In the present study, we confirmed the CAPZB expression in EpiS clinical samples and cell lines and showed that CAPZB contributes to tumor progression in the setting of EpiS by promoting cellular proliferation, invasion and migration, thus demonstrating that CAPZB functions as an oncoprotein in the pathogenesis of EpiS. 


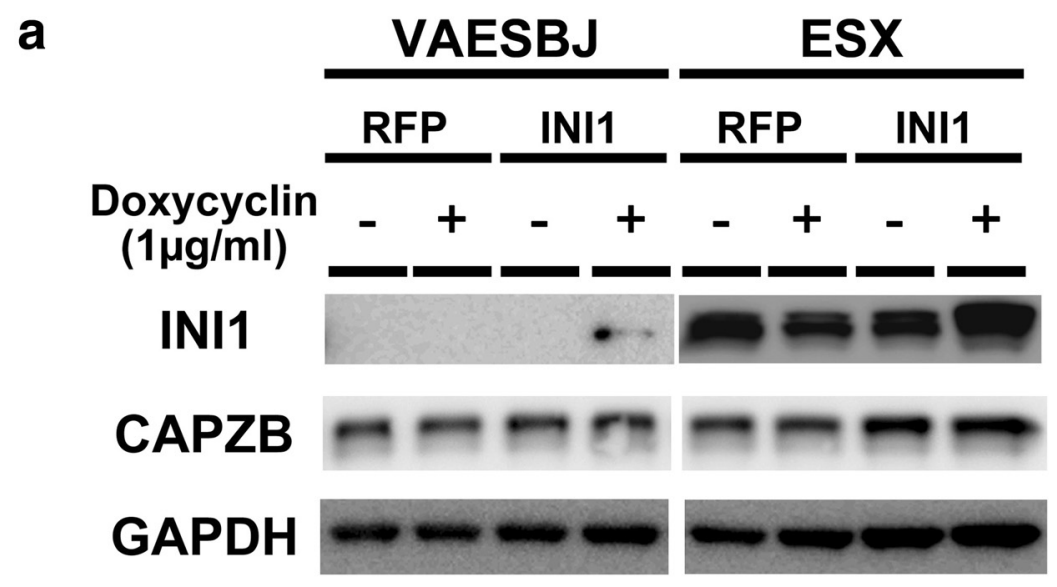

b

VAESBJ

ESX
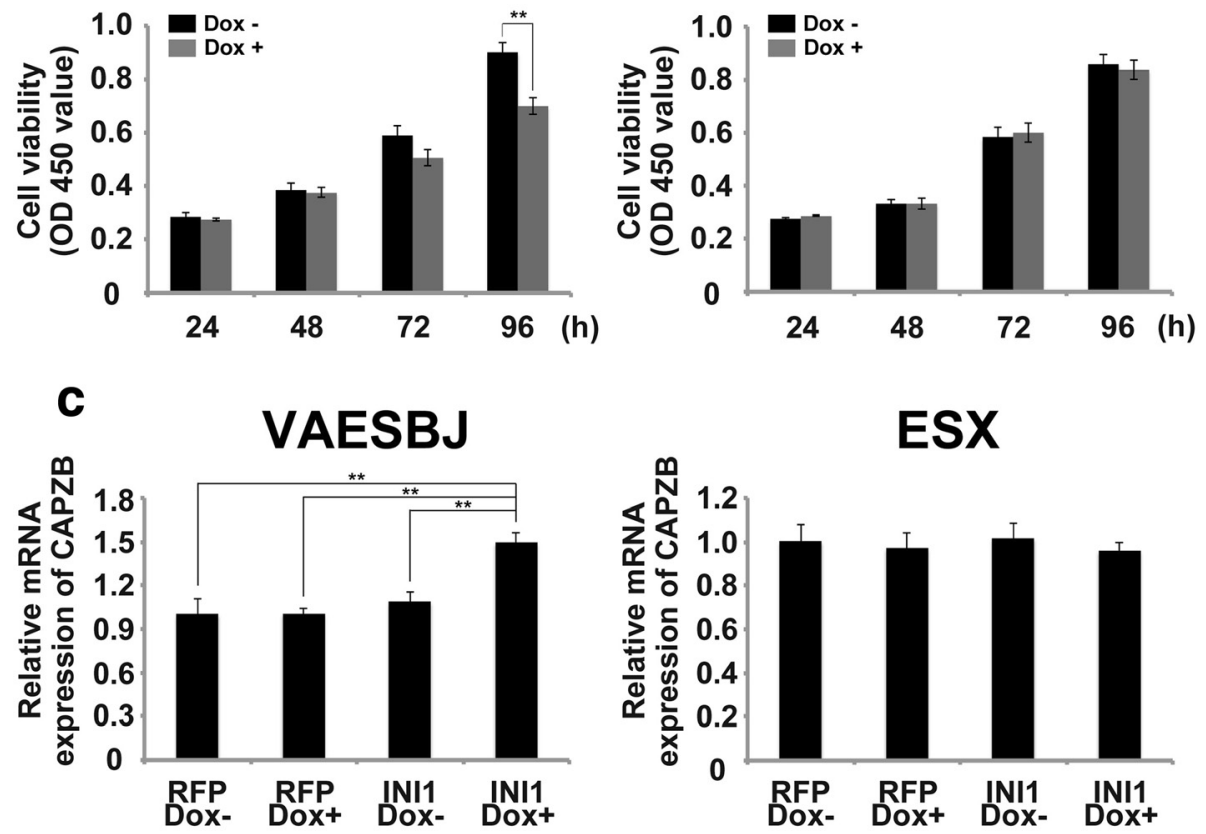

Fig. 4 The expression levels of CAPZB and cell growth in INI1-overexpressing EpiS cells. a In the VAESBJ cell line, the INI1 expression was induced in the doxycycline (Dox)-induced INI1-overexpressing cells, whereas the other three cells did not show an expression of INI1 (a, left panel). In the ESX cell line, all four cells expressed INI1, and the Dox-induced INI1-overexpressing cells had higher expression levels than the other three cells (a, right panel). Regarding the expression levels of CAPZB, the WB assay demonstrated no remarkable differences among the four types of cells for both the VAESBJ and ESX cells. $\mathbf{b}$ In the cell proliferation assay, a significant growth inhibition was observed in the Dox-induced INI1-overexpressing cells ( $p<0.01$, B, left panel). The cell proliferation assays of the ESX cells showed no significant differences in growth between the INI1-overexpressing cells and the control cells (b, right panel). c Relative expression of CAPZB mRNA in the VAESBJ and ESX cells (right and left panel, respectively). The mean expression levels of CAPZB in the RFP DOX-, RFP DOX+, INI1 Dox- and INI1 Dox + cells of each cell line, as determined using real-time PCR are shown, normalized to the expression of CAPZB mRNA in the RFP DOX- cells. In the VAESBJ cells, the INI1 Dox + cells had higher mRNA expression levels of CAPZB than the other three cells (c, left panel). On the other hand, in the ESX cells, there were no significant differences in the mRNA expression levels of CAPZB among the four cells (c, right panel)

It is also of interest to identify which biological pathways are involved in promoting the tumor progression induced by CAPZB in cases of EpiS. Therefore, we performed a proteomics study to examine changes in the protein expression profiles according to the knockdown of CAPZB. Protein profiles differentially expressed based on the knockdown of CAPZB included MX1 and BCCIP as upregulated proteins and CD44 and FLNB as downregulated proteins. Some of these proteins were identified as down stream regulator of SWI/SNF complexes 
including INI1 by using IPA analysis (Table S1 and S2). MX1, Interferon-induced GTP-binding protein MX1, was involved in antiviral responses [30, 31]. Previous proteomic study referred this protein as to be a marker of lymph node metastasis and having functional role of tumor invasion in colorectal carcinoma [32]. BCCIP, protein which interacts with BRCA2 and CDKN1A, has been implicated in many cellular processes including cell cycle regulation, DNA recombination and damage repair [33]. BCCIP suppresses the growth of certain tumor cells [34], but is required for tumor progression [35]. CD44 is a transmembranous glycoprotein which was involved in cell adhesion, cell migration, and metastasis $[36,37]$. The BRG-1 subunit of the SWI/SNF complexes is a critical regulator of CD44 expression [38]. FLNB is one of the three isoforms of filamins which were actin-binding cross linking proteins [39]. FLNs were involved in initiation of cell migration [40]. These protein profiles help to explain how CAPZB exerts its tumor-accelerating effects in EpiS tissues.

In addition, it is interesting to note that the network analyses performed after the proteomics study identified several SWI/SNF chromatin-remodeling complexes including INI1 as upstream regulators of CAPZB, although INI1 itself was not included in the differentially expressed protein list according to CAPZB knockdown. INI1 is a key member of the SWI/SNF complex, and SWI/SNF complexes play essential roles in a variety of cellular processes, including differentiation, proliferation and DNA repair. The loss of SWI/SNF subunits has been reported in a number of malignant rhabdoid cell lines and tumors, and a large number of experimental observations suggest that this complex functions as a tumor suppressor [41]. In particular, loss of the INI1 protein expression has recently been reported in other tumors as well, including most cases of EpiS [42]. These findings prompted us to investigate the possible relationship between CAPZB and INI1 in EpiS. Consequently, silencing of CAPZB definitively suppressed cell proliferation in the setting of EpiS, although, surprisingly, the expression levels of INI1, which possesses a tumor suppressor function, were decreased in the ESX cells. On the other hand, the induction of INI1 in the INI1negative EpiS cells (VAESBJ cells) definitively suppressed cell growth. Furthermore, according to INI1 induction, the CAPZB mRNA expression levels increased significantly (Fig. 4c), although the changes in the protein expression levels were not detectable by WB assays. These results suggest that the relationship between INI1 and CAPZB is complex and involves several comediators. We believe that further functional studies may help to clarify the interactions and networks between CAPZB and INI1 and that our functional and global protein expression data provide novel information for conducting such studies.

\section{Conclusions}

In summary, we found that CAPZB contributes to the cell growth and motility of EpiS cells, irrespective of the INI1 expression, highlighting a possible role of CAPZB in metastasis and tumor development in cases of EpiS. Nevertheless, the paradoxical relationship between the tumor suppressor INI1 and the oncoprotein CAPZB in EpiS remains to be clarified.

\section{Availability of data and materials}

The datasets supporting the conclusions of this article are included within the article and its additional files.

\section{Additional files}

Additional file 1: Figure S1. Localization and expression of CAPZB in remaining fourteen cases of EpiS. (JPEG $1721 \mathrm{~kb}$ )

Additional file 2: Figure S2. Localization and expression of CAPZB in remaining fourteen cases of EpiS. (JPEG $1323 \mathrm{~kb}$ )

Additional file 3: Table S1. Results of the network analyses using protein profiles of CAPZB-regulated proteins in the VAESBJ cells. (XLSX 39 kb)

Additional file 4: Table S2. Results of the network analyses using protein profiles of CAPZB-regulated proteins in the ESX cells. (XLSX 44 kb)

\begin{abstract}
Abbreviations
CAPZB: F-actin capping protein subunit beta; EpiS: Epithelioid sarcoma; I-TRAQ: Isobaric tags for relative and absolute quantitation; IPA: Ingenuity pathways analysis; SMARCB1: SWI/SNF-related matrix-associated actin-dependent regulator of chromatin subfamily B member 1 ; Cp: Capping protein; FFPE: Formalin-fixed, paraffin-embedded; IHC: Immunohistochemistry; LC-MS/MS: Liquid chromatography-tandem mass spectrometry; PCR: Polymerase chain reaction; CAPZA1: F-actin-capping protein subunit alpha-1; MX1: Interferoninduced GTP-binding protein MX1; BCCIP: BRCA2 and CDKN1A-interacting protein; SWI/SNF: Switch/sucrose non-fermentable; FLNB: Filamin B, beta.
\end{abstract}

\section{Competing interests}

The authors declare that they have no competing interests.

\section{Authors' contributions}

K.M and D.K were involved in vitro assay, immunohistochemistry, proteomic experiments and data analysis, and drafted the manuscript. K.A and M.T.I were participated by technical supports in immunohistochemistry. S.K, T.F and M.L were involved in data analysis. E.K was involved in clinical sample preparing and data interpretation. Y.S, T.Y, K.K and T.S were participated all aspects of the project. All authors read and approved the final manuscript.

\section{Acknowledgments}

This work was supported in part by a Grant-in-Aid for General Scientific Research from the Ministry of Education, Science, Sports and Culture (no. 26670286 to Tsuyoshi Saito and no. $15 \mathrm{H} 04964$ to Yoshiyuki Suehara), Tokyo, Japan.

We thank Dr. M. Emori and Dr. T. Tsukahara for the ESX cell line, Dr. Scott W. Lowe (Memorial Sloan Kettering Cancer Center, New York) for providing the plasmid, and K. Mitani for technical assistance with immunohistochemistry.

\section{Author details}

${ }^{1}$ Department of Orthopedic Surgery, School of Medicine, Juntendo University, Hongo 2-1-1, Bunkyo-ku, Tokyo 113-8421, Japan. ${ }^{2}$ Department of Medical Genomics Graduate School of Medicine, The University of Tokyo, 7-3-1 Hongo, Bunkyo-ku, Tokyo 113-0033, Japan. ${ }^{3}$ Department of Human Pathology, School of Medicine, Juntendo University, Hongo 2-1-1, Bunkyo-ku, Tokyo 113-8421, Japan. ${ }^{4}$ Division of Musculoskeletal Oncology, National Cancer Center Research Institute, 5-1-1 Tsukiji, Chuo-ku, Tokyo 104-0045, Japan. ${ }^{5}$ Laboratory of Biochemical Analysis, Central Laboratory of Medical 
Sciences, School of Medicine, Juntendo University, Hongo 2-1-1, Bunkyo-ku, Tokyo 113-8421, Japan. ${ }^{6}$ Department of Pathology, Memorial Sloan Kettering Cancer Center, 1275 York Avenue, New York, NY 10065, USA.

\section{Received: 16 April 2015 Accepted: 1 March 2016} Published online: 10 March 2016

\section{References}

1. Chase DR, Enzinger FM. Epithelioid sarcoma. Diagnosis, prognostic indicators, and treatment. Am J Surg Pathol. 1985;9(4):241-63.

2. Guillou L, Wadden C, Coindre JM, Krausz T, Fletcher CD. "Proximal-type" epithelioid sarcoma, a distinctive aggressive neoplasm showing rhabdoid features. Clinicopathologic, immunohistochemical, and ultrastructural study of a series. Am J Surg Pathol. 1997;21(2):130-46.

3. Hasegawa T, Matsuno Y, Shimoda T, Umeda T, Yokoyama R, Hirohashi S. Proximal-type epithelioid sarcoma: a clinicopathologic study of 20 cases. Mod Pathol. 2001;14(7):655-63.

4. Modena P, Lualdi E, Facchinetti F, Galli L, Teixeira MR, Pilotti S, et al. SMARCB1/INI1 tumor suppressor gene is frequently inactivated in epithelioid sarcomas. Cancer Res. 2005;65(10):4012-9.

5. Le Loarer F, Zhang L, Fletcher CD, Ribeiro A, Singer S, Italiano A, et al. Consistent SMARCB1 homozygous deletions in epithelioid sarcoma and in a subset of myoepithelial carcinomas can be reliably detected by FISH in archival material. Genes Chromosomes Cancer. 2014;53(6):475-86.

6. Chbani L, Guillou L, Terrier P, Decouvelaere AV, Gregoire F, Terrier-Lacombe MJ, et al. Epithelioid sarcoma: a clinicopathologic and immunohistochemical analysis of 106 cases from the French sarcoma group. Am J Clin Pathol. 2009;131(2):222-7.

7. Hornick JL, Dal Cin P, Fletcher CD. Loss of INI1 expression is characteristic of both conventional and proximal-type epithelioid sarcoma. Am J Surg Pathol. 2009;33(4):542-50.

8. Brenca M, Rossi S, Lorenzetto E, Piccinin E, Piccinin S, Rossi FM, et al. SMARCB1/INI1 genetic inactivation is responsible for tumorigenic properties of epithelioid sarcoma cell line VAESBJ. Mol Cancer Ther. 2013;12(6):1060-72.

9. Mukaihara K, Kubota D, Yoshida A, Asano N, Suehara Y, Kaneko K, et al. Proteomic profile of epithelioid sarcoma. J Proteomics Bioinform. 2014;7(6):158-65.

10. Zigmond $\mathrm{SH}$. Beginning and ending an actin filament: control at the barbed end. Curr Top Dev Biol. 2004:63:145-88.

11. Bai SW, Herrera-Abreu MT, Rohn JL, Racine V, Tajadura V, Suryavanshi N, et al. Identification and characterization of a set of conserved and new regulators of cytoskeletal organization, cell morphology and migration. BMC Biol. 2011;9:54.

12. Park HW, Shin JS, Kim CW. Proteome of mesenchymal stem cells. Proteomics. 2007;7(16):2881-94.

13. Zhou Q, Chaerkady R, Shaw PG, Kensler TW, Pandey A, Davidson NE. Screening for therapeutic targets of vorinostat by SILAC-based proteomic analysis in human breast cancer cells. Proteomics. 2010;10(5):1029-39.

14. Hong WX, Ye JB, Chen MT, Yan Y, Zhou GF, Yang XF, et al. Trichloroethylene induces biphasic concentration-dependent changes in cell proliferation and the expression of SET-associated proteins in human hepatic L-02 cells. Biomed Environ Sci. 2013;26(7):618-21.

15. Shimada K, Uzawa K, Kato M, Endo Y, Shiiba M, Bukawa H, et al. Aberrant expression of RAB1A in human tongue cancer. Br J Cancer. 2005;92(10):1915-21.

16. Vignjevic D, Montagnac G. Reorganisation of the dendritic actin network during cancer cell migration and invasion. Semin Cancer Biol. 2008;18(1):12-22.

17. Carlier MF, Pantaloni D. Control of actin dynamics in cell motility. J Mol Biol. 1997:269(4):459-67.

18. Hopmann R, Cooper JA, Miller KG. Actin organization, bristle morphology, and viability are affected by actin capping protein mutations in Drosophila. J Cell Biol. 1996;133(6):1293-305.

19. Cooper JA, Sept D. New insights into mechanism and regulation of actin capping protein. Int Rev Cell Mol Biol. 2008;267:183-206.

20. Jo WY, Fletcher CD: WHO classification of soft tissue tumours: an update based on the 2013 (4th) edition. Pathology. 2014;46(2):95-104.

21. Emori M, Tsukahara T, Murase M, Kano M, Murata K, Takahashi A, et al. High expression of CD109 antigen regulates the phenotype of cancer stem-like cells/cancer-initiating cells in the novel epithelioid sarcoma cell line ESX and is related to poor prognosis of soft tissue sarcoma. PLoS One. 2013;8(12):e84187.
22. Herbrich SM, Cole RN, West Jr KP, Schulze K, Yager JD, Groopman JD, et al. Statistical inference from multiple iTRAQ experiments without using common reference standards. J Proteome Res. 2013;12(2):594-604.

23. Kobayashi D, Kumagai J, Morikawa T, Wilson-Morifuji M, Wilson A, Irie A, et al. An integrated approach of differential mass spectrometry and gene ontology analysis identified novel proteins regulating neuronal differentiation and survival. Mol Cell Proteomics. 2009;8(10):2350-67.

24. Glen A, Gan CS, Hamdy FC, Eaton CL, Cross SS, Catto JW, et al. iTRAQfacilitated proteomic analysis of human prostate cancer cells identifies proteins associated with progression. J Proteome Res. 2008;7(3):897-907.

25. Noirel J, Evans C, Salim M, Mukherjee J, Yen OS, Pandhal J, et al. Methods in quantitative proteomics: setting iTRAQ on the right track. Curr Proteomics. 2011:8(1):17-30.

26. Datta A, Park JE, Li X, Zhang H, Ho ZS, Heese K, et al. Phenotyping of an in vitro model of ischemic penumbra by iTRAQ-based shotgun quantitative proteomics. J Proteome Res. 2010;9(1):472-84.

27. Bourassa S, Fournier F, Nehme B, Kelly I, Tremblay A, Lemelin V, et al. Evaluation of ITRAQ and SWATH-MS for the quantification of proteins associated with insulin resistance in human duodenal biopsy samples. PLoS One. 2015;10(5):e0125934.

28. Lee YJ, Jeong SH, Hong SC, Cho BI, Ha WS, Park ST, et al. Prognostic value of CAPZA1 overexpression in gastric cancer. Int J Oncol. 2013:42(5):1569-77.

29. Thompson CC, Ashcroft FJ, Patel S, Saraga G, Vimalachandran D, Prime W, et al. Pancreatic cancer cells overexpress gelsolin family-capping proteins, which contribute to their cell motility. Gut. 2007;56(1):95-106.

30. Horisberger MA, Hochkeppel HK. IFN-alpha induced human 78 kD protein: purification and homologies with the mouse Mx protein, production of monoclonal antibodies, and potentiation effect of IFN-gamma. J Interferon Res. 1987;7(4):331-43.

31. Horisberger MA. Interferons, Mx genes, and resistance to influenza virus Am J Respir Crit Care Med. 1995:152(4 Pt 2):S67-71.

32. Croner RS, Sturzl M, Rau T, Metodieva G, Geppert Cl, Naschberger E, et al. Quantitative proteome profiling of lymph node-positive vs. -negative colorectal carcinomas pinpoints MX1 as a marker for lymph node metastasis. Int J Cancer. 2014;135(12):2878-86.

33. Liu X, Cao L, Ni J, Liu N, Zhao X, Wang Y, et al. Differential BCCIP gene expression in primary human ovarian cancer, renal cell carcinoma and colorectal cancer tissues. Int J Oncol. 2013;43(6):1925-34

34. Liu J, Yuan Y, Huan J, Shen Z. Inhibition of breast and brain cancer cell growth by BCCIPalpha, an evolutionarily conserved nuclear protein that interacts with BRCA2. Oncogene. 2001;20(3):336-45.

35. Huang YY, Dai L, Gaines D, Droz-Rosario R, Lu H, Liu J, et al. BCCIP suppresses tumor initiation but is required for tumor progression. Cancer Res. 2013:73(23):7122-33.

36. Goodison S, Urquidi V, Tarin D. CD44 cell adhesion molecules. Mol Pathol. 1999:52(4):189-96.

37. Martin TA, Harrison G, Mansel RE, Jiang WG. The role of the CD44/ezrin complex in cancer metastasis. Crit Rev Oncol Hematol. 2003:46(2):165-86.

38. Strobeck MW, DeCristofaro MF, Banine F, Weissman BE, Sherman LS, Knudsen ES. The BRG-1 subunit of the SWI/SNF complex regulates CD44 expression. J Biol Chem. 2001;276(12):9273-8.

39. Nakamura F, Stossel TP, Hartwig JH. The filamins: organizers of cell structure and function. Cell Adh Migr. 2011;5(2):160-9.

40. Baldassarre M, Razinia Z, Burande CF, Lamsoul I, Lutz PG, Calderwood DA. Filamins regulate cell spreading and initiation of cell migration. PLoS One. 2009;4(11):e7830.

41. Reisman D, Glaros S, Thompson EA. The SWI/SNF complex and cancer. Oncogene. 2009;28(14):1653-68.

42. Kohashi K, Izumi T, Oda Y, Yamamoto H, Tamiya S, Taguchi T, et al. Infrequent SMARCB1/INI1 gene alteration in epithelioid sarcoma: a useful tool in distinguishing epithelioid sarcoma from malignant rhabdoid tumor. Hum Pathol. 2009:40(3):349-55. 